Historic, Archive Document

Do not assume content reflects current scientific knowledge, policies, or practices. 



\section{The USDA's Role in Equine Health Monitoring}

The United States Department of Agriculture has had a role in assuring the health and well being of U.S. livestock since 1884. At that time, agriculture relied on the horse for transportation, to work fields, and to facilitate the movement of cattle on ranches and to market. Although the horse's prominence as a source of transportation and power faded rapidly with the advent of motorized vehicles, horses are still integral to U.S. agriculture.

\section{U.S. Equine and Livestock Population Patterns}

Historically, agriculture production was supported by the family farm unit producing a full range of crops and livestock. For example, data from the 1900 Census of Agriculture show 82 percent of all farms had cattle, 76 percent had hogs and 79 percent had horses.

In contrast, today (1992 Census) pork production has become highly concentrated on only 10 percent of the farms while total inventory has declined only slightly. Cattle production still remains widely dispersed on 56 percent of all farms while total inventory has increased by 42 percent. Only 18 percent of farms today have horses. The 1992 Census reported 338,346 farms with 2,049,522 horses. However, it should be noted that these data are limited to those horses on farms.

\section{Total Number of Head on Farms}

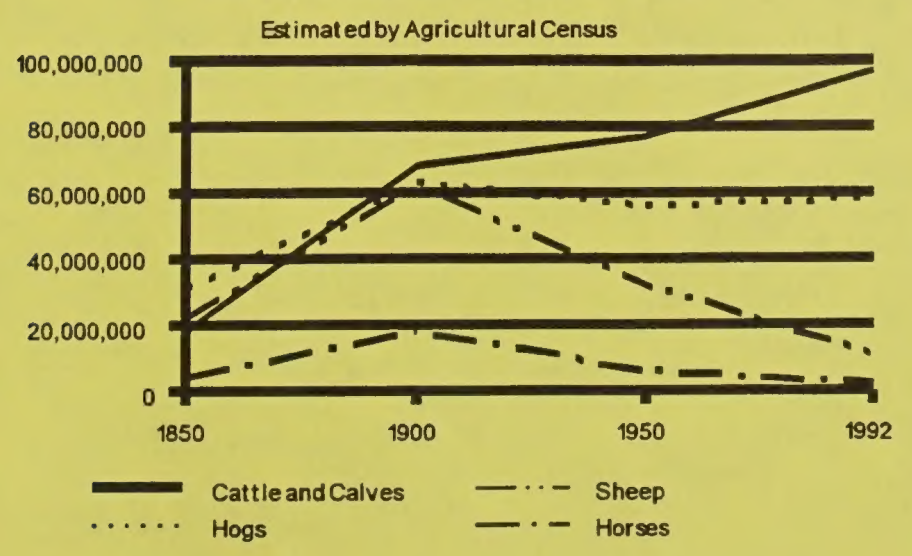

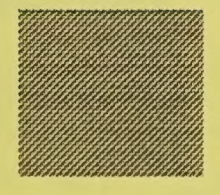

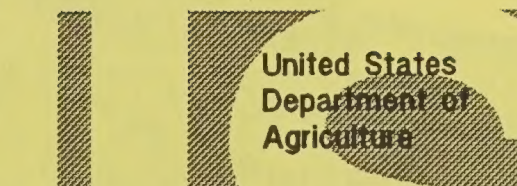
A farm as defined by both the Census and USDA is any place
that produced arodhsold $\$ 1,000$ or more in agricultural products. If horses would not) a point system is utilized to include operations with livestock or crops. A place with pasture (no points awarded), no crop production, and no livestock inventory or sales would need five horses to be considered a farm. Under these criteria, many places with fewer than five horses are excluded from the Census data. Service-oriented places, such as racetracks and boarding facilities, are also excluded. This farm definition may exclude over one-half of the horse population in the U.S. Independent studies by the American Horse Council (AHC, 1987) and the American Veterinary Medical Association (AVMA, 1991) suggest roughly 5 million horses exist in the U.S. The exclusion of the non-farm horse population from the Census data, which may be as many as 3 million head, clearly suggests the need to collect data on the entire population.

A prerequisite to the evaluation of animal health is to know the demographics of that industry. The Agriculture Census enumerates livestock populations every 5 years. Food and fiber animal numbers are more actively tracked by USDA's National Agricultural Statistics Service (NASS) which estimates major livestock populations at least annually. Currently, comprehensive demographics do not exist for the equine industry. NASS, being the principle source for estimates of animal inventories in the U.S., is the logical source to fill this critical information gap.

\section{USDA and Equine Health}

In 1996, the USDA considers the welfare and health of horses important for several reasons:

1) The horse industry expends large amounts of money for agricultural products. The modern horse industry is multifaceted with many breeds and varied uses, including, but not limited to: breeding, racing, showing, competitions (i.e., rodeo, 3-day eventing), teaching tools (i.e., 4-H projects, handicap riding programs), pleasure riding, transportation in the National Parks, working on cattle ranches and feedlots, police mounts, and companion animals.

Although the industry's diversity complicates a measure of economic value derived from equine ownership or products, several states have performed economic impact studies of the 
horse industry and found substantial value to agriculture based on purchases of agricultural products and veterinary services. Estimates of equine numbers and related expenditures in New Jersey (1987), New York (1988), Pennsylvania (1990), and Michigan (1992) revealed horse owners in these states spent from $\$ 35.1$ million to $\$ 91.0$ million per year on feed alone. Total equine-related expenditures per state ranged from $\$ 253$ million to $\$ 631$ million annually for feed, bedding, veterinary care, farrier care, hired labor, taxes, rent, tack, boarding, and capital improvements. In 1987, the AHC estimated overall horse-related expenditures nationally at $\$ 15$ billion dollars per year.

The equine industry can be compared to other livestock and poultry industries in terms of the total amount of feed consumed. The USDA estimates the equine industry uses an amount of feed equivalent to 40 percent of that for the broiler industry, 18 percent of the feedlot cattle industry, 16 percent of the pork industry, and 15 percent of the dairy industry.

2) The U.S. needs to assure quality of exported horse meat for consumption by humans. Horses are slaughtered in the U.S. every year and exported for human consumption, primarily to Europe. In U.S. plants, carcass inspection numbers totaled 259,000 in $1992 ; 189,000$ in 1993; and 115,000 in 1994. The USDA's Food Safety Inspection Service maintains quality assurance for equine as well as other livestock carcasses for human consumption. The reported monetary value of these exported carcasses in 1995 was $\$ 67.5$ million.

3) U.S. agriculture recognizes the need to monitor diseases shared by horses, other livestock, and man. A 1995 outbreak of vesicular stomatitis virus (VSV) pointed out a need for the USDA to monitor infectious diseases which affect both horses and traditional livestock such as cattle. Other diseases, such as Equine Infectious Anemia, pose a risk of infection to other horses. The USDA must have knowledge of horse demographics and movements to position staff to respond to such outbreaks.

Horses play a potential role in zoonotic diseases such as Venezuelan Equine Encephalitis (VEE). VEE outbreaks occurred in Venezuela in May of 1995 and spread to the northernmost state of LaGuajira, Columbia, by September of the same year. Recent reports indicate that over 15,000 people have been infected with VEE, and 42 related deaths have been reported. Equine fatalities have been estimated at 500 during the same time period. This outbreak of a zoonotic disease for which the horse is a viral amplifier points out the need for USDA to be in a position to respond efficiently and effectively to such a threat in the U.S. The USDA could play a pivotal role in supplying information on the location of equine populations and the number of doses of vaccine needed from pharmaceutical companies to prevent or stem an outbreak of VEE in this country.

4) As with other livestock industries, global trade figures prominently for the equine industry. In 1995, the value of permanent live horse exports from the U.S. was reported at $\$ 285$ million. This figure can be compared to $\$ 86$ million for live cattle exports. Global trade and potential regionalization efforts will require accurate information on the demographics of the U.S. horse population. The USDA currently addresses equine health issues, both domestic and international, at both the national staff and field levels. The addition of equine population demographics will greatly strengthen these efforts.

5) Livestock industries expressed their need for USDA to address equine disease outbreaks at the 1995 U.S. Animal Health Association meeting where they charged the department to be more knowledgeable about the epidemiology of VSV.

Earlier, a 1974 report from the Special Panel of the Committee on Animal Health from the Agricultural Board of the National Research Council (published by the National Academy of Sciences and supported in part by the USDA) proposed formation of a "Center" to meet animal industries' needs for data regarding animal health management (Library of Congress, No. 74-19048). The report detailed a Center that would serve as a national focal point for collecting, compiling, and analyzing data and disseminating information on the incidence, prevalence, and costs of animal disease. The Center would monitor diseases in food animals, but also diseases of horses and ponies.

The role of the Center described by the 1974 committee report parallels a mission statement developed by the USDA:Animal and Plant Health Inspection Service:Veterinary Services, Centers for Epidemiology and Animal Health (CEAH). As horses are clearly mentioned as one of many animal species to be monitored by the proposed "Center," it is appropriate that CEAH, along with other USDA collaborators, are in the planning stages for a national equine health monitoring program in 1998.

As an initial step in the planning process, a Catalog of Opportunities for Equine Health Monitoring has been developed. The catalog discusses the advantages and limitations of a wide variety of monitoring options using existing data.

For more information, contact:

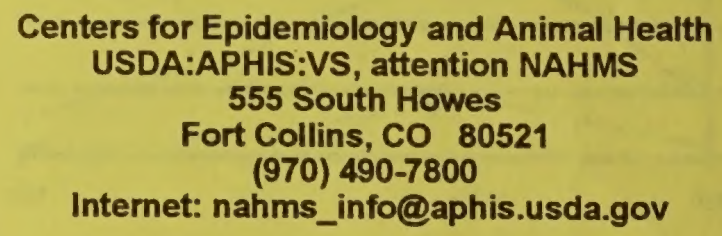

N207.596 